\title{
Oral Health Knowledge and Attitude as Determinants of Oral Health Behavior in a Sample of Old People in Port Harcourt, Rivers State, Nigeria
}

\author{
Braimoh Omoigberai Bashiru ${ }^{1,}$, , Achalu Ernest ${ }^{2}$, Okpako Johnson Egodotaire ${ }^{2}$ \\ ${ }^{1}$ Department of Preventive Dentistry, Faculty of Dentistry, College of Health Sciences, University of Port Harcourt, Choba, Port Harcourt, \\ Nigeria \\ ${ }^{2}$ Department of Human Kinetics and Health Education, Faculty of Education, University of Port Harcourt, Choba, Port Harcourt, Nigeria
}

Email address:

omoigberai.braimoh@uniport.edu.ng (B. O. Bashiru), ernest.achalu@uniport.edu.ng (A. Ernest), okpakojef@gmail.com (O. J. Egodotaire) ${ }^{*}$ Corresponding author

\section{To cite this article:}

Braimoh Omoigberai Bashiru, Achalu Ernest, Okpako Johnson Egodotaire. Oral Health Knowledge and Attitude as Determinants of Oral Health Behavior in a Sample of Old People in Port Harcourt, Rivers State, Nigeria. European Journal of Preventive Medicine.

Vol. 5, No. 4, 2017, pp. 45-50. doi: 10.11648/j.ejpm.20170504.12

Received: June 14, 2017; Accepted: June 28, 2017 Published: July 27, 2017

\begin{abstract}
Adequate oral health knowledge, attitude and behavior are very important for the improvement of patient's oral health. The objective of the study was to assess the oral health knowledge, attitude and behavior of elderly people in Port Harcourt and determine the relationship between these variables. The research was descriptive survey and correlational in design. A total of 543 old people were selected by systematic random sampling. Data was collected with a self-developed Oral Health Assessment Questionnaire (OHAQ) designed in four sections (A-D) and analysed using SPSS version 20 (IBM SPSS Armonk, New York). Relationship between variables was established by simple regression and significance determined at 0.05 alpha level. Majority (63\%) and (66\%) of the pensioners in Port Harcourt Rivers State had poor knowledge of oral health and negative attitude toward oral health respectively. About $60 \%$ of the participants had poor oral health behavior. Oral health knowledge and attitude accounted for $43.56 \%\left(\mathrm{R}^{2}=0.4356\right)$ and $22.09 \%\left(\left(\mathrm{R}^{2}=0.2209\right)\right.$ respectively of the variance in the behavior of the pensioners. There was a significant moderate and positive relationship between oral health knowledge and behavior $(\mathrm{R}=0.66)$ and between oral health attitude and behavior $(\mathrm{R}=0.47)$. The present study showed that oral health knowledge and attitude of the respondents significantly and moderately predicted their oral health behavior. There is therefore the need to educate this group on appropriate oral self-care and regular dental visits as a cornerstone to the promotion of oral health and prevention of oral diseases.
\end{abstract}

Keywords: Elderly, Oral Health Behavior, Oral Self-Care, Prediction

\section{Introduction}

Oral diseases are clearly related to behavior, the prevalence of dental caries and periodontal disease has decreased with improvements in oral hygiene and a decrease in the consumption of sugar products [1]. The primary concern of oral health educators is to impact a positive oral health knowledge and behavior in the society. Education is important for the adoption of informed lifestyle choices among individuals [2]. Studies have shown that there is an association between knowledge and better oral health $[3,4]$. This knowledge is usually obtained from information which subsequently translates into action. Behavior is an outcome measure when an action is sustained. Therefore, adequate oral health knowledge, attitude and behavior are very important for the improvement of patient's oral health $[5,6]$.

The attitude of an individual towards performing a particular behavior may be used as a predictor of certain behavioral outcomes $[5,6]$. Regarding oral health, it has been shown that those with high concern for their oral health are more likely to partake in healthy oral health behaviors. AlAnsari et al. [5], showed that negative oral health behavior is correlated to low concerns for oral health. Therefore, evaluating individuals' oral health knowledge and attitudes 
may help provide understanding of their oral health behaviors. A considerable body of research has focused on understanding why and under what circumstances individuals engage in health behavior directed towards prevention [7]. Most of the researches were done within the frame work of the Health Belief Model (HBM). The underlying concept of the HBM is that health behavior is determined by personal beliefs or perceptions about a disease and the strategies available to decrease its occurrence $[8,9]$. The model focuses on variables influencing an individual's control over a specific action and uses these same variables to predict behavior and stipulates that if an individual has the correct knowledge relating oral diseases; finds the health behavior important to them and knows that a form of treatment exists; the HBM predicts the individual will be ready to change. Therefore, the HBM allowed the researchers in this study to assess the oral health knowledge, attitude and behavior of old people in Port Harcourt, Rivers State; and further assess the influence of oral health knowledge and attitude on oral behavior.

The population for this study was pensioners (Retired government workers) in Port Harcourt, Rivers State. This population group was selected for the study because they are 60 years and above. This coincides with the age at which the workers proceed on retirement from civil service. According to the United Nation Population Division [10], the Nigerian National Population Commission define the elderly in Nigeria as person's age 60 years and over, therefore, the pensioners were considered as elderly in the present study and the two terms were used interchangeably. Data on oral health among the elderly in Nigeria are sparse, to the best of the researchers' knowledge none of these studies have looked at the influence of oral health knowledge and attitude on oral health behavior among the elderly. The objective of this study therefore, was to find out the proportion of the elderly with: good and poor knowledge of oral health, good and poor oral health behavior and, positive and negative attitudes towards oral health in Port Harcourt, Rivers State, Nigeria. The study also investigated the relationship between oral health knowledge and oral health behavior as well as between oral health attitude and oral health behavior. The researchers hypothesized that there will be no significant relationship between oral health knowledge and behavior and between oral health attitude and behavior.

\section{Subjects and Methods}

\subsection{Research Design}

According to Nwankwo more than one research design could be used for a study [11]. The research design employed in this study was a combination of descriptive survey and correlational design. Descriptive survey design is a study design in which the researcher collects data from a large sample drawn from a given population and describes certain features of the sample as they are at the time of study and which are of interest to the researcher [11]. Thus in this study the researcher compared the oral health behavior, dental caries and oral hygiene status of the pensioners in relation to their gender, age, educational status and retirement grade level. Correlational design according to Nworgu, is the type of study that seeks to establish what relationship exists between two or more variables [12]. Usually, such studies indicate the direction and magnitude of the relationship between the variables. Thus, the present study is correlational in part because the researcher collected data on oral health knowledge, attitude and behavior from the sample and the scores from these variables were correlated using simple regression. Furthermore, the direction and magnitude of the relationship was determined.

\subsection{Population for the Study}

The population of the study consisted of 3,624 pensioners in Port Harcourt, Rivers State. Pensioners comprise of old people that cut across gender, educational and economic status, which are known determinant of health. The group was considered as elderly since it comprised of old people 60 years and above.

\subsection{Sample and Sampling Technique}

The sample size (n) was determined according to the formula for sample size determination by Lwanga and Lemeshow [13] given as $n=\frac{z^{2} p q}{d^{2}}$ for population less than 10 , 000 at $95 \%$ confidence interval, standard normal deviate $(\mathrm{z})$ of 1.96 and degree of accuracy (d) 0.05 . The proportion (p) of elderly with dental caries was $0.305(30.5 \%)$ [14], and the proportion (q) without dental caries was 0.695 (69.5\%). Therefore, the minimum sample size obtained for this study was 325 .

The subjects were selected by systematic random sampling. The selection was done at the Secretariat of the Nigerian Union of Pensioners (NUP) located at the State Civil Service Secretariat in Port Harcourt. Pensioners in Rivers State routinely visit the Secretariat daily and congregate once monthly for their meetings. The register of the pensioners constituted the sampling frame for this study (source: NUP Secretariat) and every second subject was selected from the register. Subjects selected who were not present in a particular visit were contacted through their phone numbers for subsequent visit.

\subsection{Instrument for Data Collection}

Data for this study was from primary source. Data was collected by the use of questionnaire. The questionnaire was a structured self-developed Oral Health Assessment Questionnaire (OHAQ) designed in four sections (A-D). Section A contained information on socio-demographic data; section B, C and D on oral health knowledge, behavior and attitudes respectively. Section A contained the demographic information (gender, age, retirement grade level and educational status), section $\mathrm{B}$ and $\mathrm{C}$ contained questions on oral health knowledge and behavior both were assessed on a scale of yes ( 1 point) or no ( 0 point) for positively 
constructed questions and yes (0 point) or no (1) for negative questions. Oral health knowledge was assessed using 20 item questions and behavior with 16 item questions. The oral health attitude of the pensioners was contained in section D and it had 13 questions. The questions were assessed on a 4 point modified Likert scale of strongly agree (4 points) agree ( 3 points), disagree ( 2 points) and strongly disagree ( 1 point) for positive questions and strongly agree (1 point), agree (2 points), disagree ( 3 points) and strongly disagree ( 4 points) for negative questions.

\subsection{Validity and Reliability of the Instrument}

Validity as defined by Kumar 2011, refer to the accuracy, quality and appropriateness of the modalities adopted for finding answers to the research questions [15]. The researcher believes that this research study is accurate and valid due to the fact that procedures adopted for this study are from scientific and peer reviewed sources. The validity was further justified by presenting the data collecting instrument to the second and third author and based on their expert opinion, comments, criticisms and observations the instrument was modified.

The reliability of the instrument was done using pensioners different from those recruited for the study. Twenty of them were selected; the selected pensioners completed the questionnaire and were examined by the researcher. The filling of the questionnaire and examination was repeated after an interval of one week. The reliability of the instrument was determined using the Cronbach alpha and alpha coefficient of 0.82 was obtained. The reliability testing also served as the pilot-test for the data collecting instrument, from the reaction of the participants to the questionnaire, it was evident that they quite understood the question items. There was evidence that some words were not understood under attitude and knowledge section. This were identified and modified according to the level of participants understanding.

\subsection{Procedure for Data Collection}

Five trained research Assistants were used to ensure proper distribution of the questionnaire to the participants. Rapport was established with the pensioners, the researcher and trained research Assistants explained the purpose of the research to the pensioners and highlighted the importance of privacy, confidentiality and consent. Several visits were made to the Secretariat and at each visit questionnaires were distributed to pensioners for completion. Five hundred and forty three (543) copies of the questionnaire were administered to the respondents and all were retrieved. This took a period of two years from April 2015- March 2017. The study was approved by the Research Ethics Committee, University of Port Harcourt. Pensioners who retired from public service of Rivers State government voluntarily or retired as a result of years of service, who were below the age of 60 years were excluded from the study, since they do not meet the age to be classified as elderly.

\subsection{Procedure for Data Analysis}

The completed copies of the questionnaires were collated, coded and entered into the Statistical Package for Social Sciences (SPSS) spread sheet. The data was subsequently analyzed using SPSS version 20 (IBM SPSS Armonk, New York). Descriptive statistics of percentage, mean and standard deviation were used describe the oral health knowledge, attitude and behavior of the subjects. Individual knowledge score varied from 0-20. The mean score for the population was calculated and respondents with Knowledge score equal to or greater than the population mean score were rated as having good knowledge and those with score less than the mean were rated as having poor knowledge. The behavior score of individual varied from 0-16. Pensioners with behavior score equal to or greater than the population mean oral health behavior score were graded as having good behavior and those with score less than the mean were graded as having poor behavior. Similarly, attitude score for individual varied from 13-52. Participants with attitude score equal to or greater than the population mean attitude score were regarded as having positive attitude and those with score less than the mean were regarded as having negative attitude.

Inferential statistics of simple regression was used to test the association between oral health knowledge, attitude and behavior, the hypotheses were rejected if the F-calculated values were equal to or greater than their respective Fcritical values. In addition, the hypotheses were rejected if the p-value was less than the alpha level of 0.05 and accepted if the p-value was equal to or greater than the alpha level of 0.05 . Interpretation of the nature of relationship between independent and dependent variables was done according to Nwana [16]. According to Nwana, 00-0.19 implies "no relationship or very low relationship", 0.20-0.39 "low relationship", $0.40-0.69$ "moderate relationship", 0.70-0.89 "high relationship" and 0.90-1.00 "very high relationship"

\section{Results}

There were more male pensioners than female pensioners, $295(54.3 \%)$ were males and 248 (45.7\%) were females. There were also more respondents in the 60-64 years age group $234(43.1 \%)$, the age group 65-69 years constituted $206(37.9 \%)$ of the respondents and 103 $(19.0 \%)$ of the respondents were $\geq 70$ years. Regarding educational status, $119(21.9 \%), 198(36.5 \%)$ and 226 $(41.6 \%)$ had primary, secondary and tertiary education respectively. A total of 277 (51\%) of the pensioners retired on level 1-6, while $266(49 \%)$ of the pensioners retired on level 7-17 (Table 1).

Table 2 shows that the mean knowledge score of the participants was 12.23 ( $\mathrm{SD}=1.57$ ). Majority of the participants $342(63.0 \%)$ had poor oral health knowledge with score less than the sample mean and 201 (37.0\%) had good knowledge of oral health with score equal to or greater 
than the sample mean. The mean behavior score of the participants was $8.76(\mathrm{SD}=1.10)$. More than half of the participants $319(58.7 \%)$ had poor oral health behavior with score less than the sample mean and $224(41.3 \%)$ had good oral health behavior with score equal to or greater than the sample mean (Table 2). Regarding attitude, the mean attitude score of the respondents was $27.61(\mathrm{SD}=1.31)$. Majority of the respondents $361(66.5 \%)$ had negative oral health attitude with score less than the sample mean and $182(33.5 \%)$ had positive oral health attitude with score equal to or greater than the sample mean (Table 2).

Table 1. Distribution of the Respondents Based on Gender, Age, Educational Status and Retirement Grade Level.

\begin{tabular}{lll}
\hline Variables & Frequency & Percent \\
\hline Gender & & \\
Female & 248 & 45.7 \\
Male & 295 & 54.3 \\
Total & 543 & 100 \\
Age & & \\
60-64 years & 234 & 43.1 \\
65-69 years & 206 & 37.9 \\
770 years & 103 & 19.0 \\
Total & 543 & 100 \\
Educational Status & & \\
Primary & 119 & 21.9 \\
Secondary & 198 & 36.5 \\
Tertiary & 226 & 41.6 \\
Total & 543 & 100 \\
Retirement Grade Level & & \\
1-6 & 277 & 51.0 \\
7-17 & 266 & 49.0 \\
Total & 543 & 100 \\
\hline
\end{tabular}

Table 2. Oral Health Knowledge, Attitude and Behavior of the pensioners in Port Harcourt, Rivers State.

\begin{tabular}{lllll}
\hline Variables & Frequency & Percent & Mean & SD \\
\hline Knowledge & & & & \\
Poor knowledge & 342 & 63.0 & 10.05 & 1.25 \\
Good Knowledge & 201 & 37.0 & 14.40 & 1.87 \\
Total & 543 & 100 & 12.23 & 1.57 \\
Behavior & & & \\
Poor behavior & 319 & 58.7 & 7.38 & 1.22 \\
Good behavior & 224 & 41.3 & 10.12 & 0.89 \\
Total & 543 & 100 & 8.76 & 1.10 \\
Attitude & & & & \\
Negative attitude & 361 & 66.5 & 25.48 & 0.77 \\
Positive attitude & 182 & 33.5 & 29.72 & 1.84 \\
Total & 543 & 100 & 27.61 & 1.31 \\
\hline
\end{tabular}

Table 3 shows simple regression analysis of the relationship between oral health knowledge and behavior of the pensioners. The table shows that oral health knowledge accounts for $43.56 \%\left(\mathrm{R}^{2}=0.4356\right)$ of the variance in the behavior of the pensioners. The regression coefficient $(\mathrm{R})$ was 0.66 indicating a moderate positive relationship between oral health knowledge and behavior. Furthermore, the calculated F-value (8.06) was greater than the critical F-value (3.84) with the degrees of freedom (1 and 541) and at 0.05 alpha level. The null hypothesis was consequently rejected. Therefore, oral health knowledge of the pensioners was significantly related to their oral health behavior. Further analysis of the relationship in a regression model showed that the p-value (0.000) was less than 0.05 alpha level, this further confirmed the significant relationship between oral health knowledge and behavior.

Table 3. Simple Regression of the Relationship between Oral Health Knowledge and Behavior of the Pensioners.

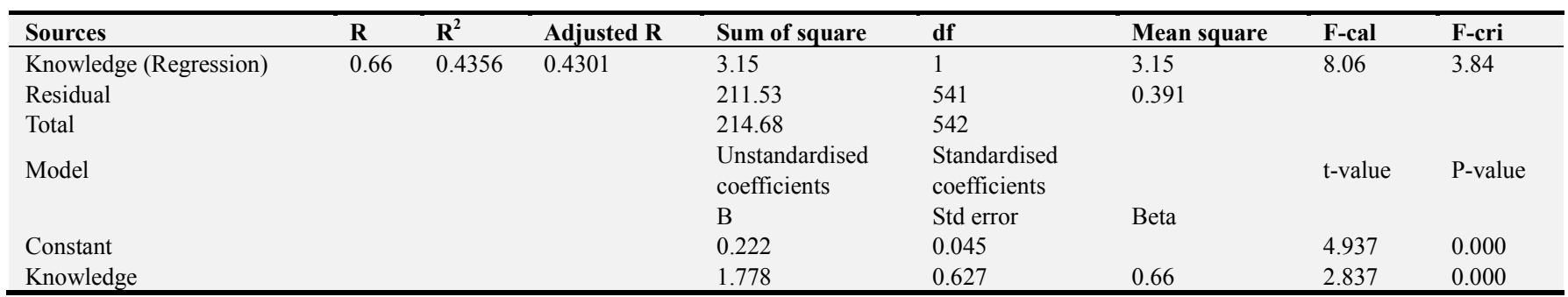

Table 4. Simple Regression analysis of the Relationship between oral health attitude and behavior of the pensioners.

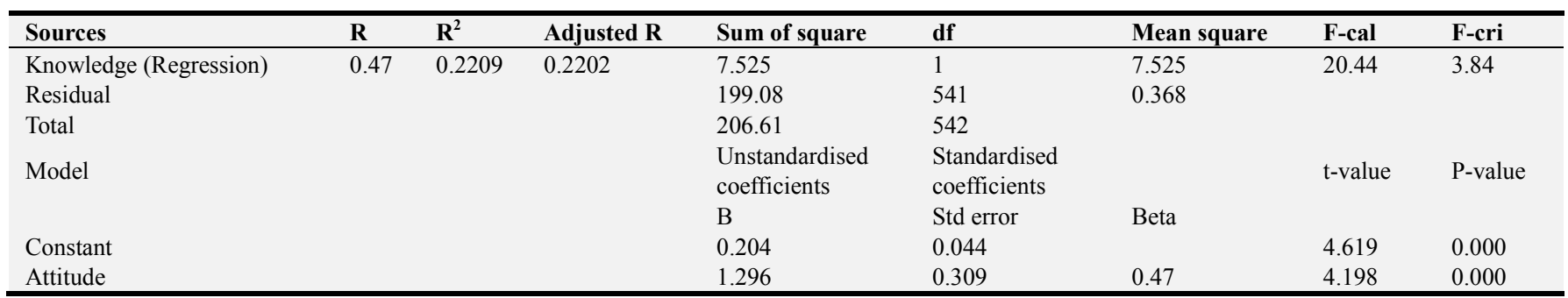

Simple regression analysis of the relationship between oral health attitude and behavior of the pensioners is shown in Table 4. The result indicates that oral health attitude accounts for $22.09 \%\left(\left(\mathrm{R}^{2}=0.2209\right)\right.$ of the variance in the behavior of the pensioners. The regression coefficient $(R)$ was 0.47 suggesting a moderate and positive relationship between oral health attitude and behavior. In addition, table 4 also shows that the calculated F-value (20.44) was greater than the critical F-value (3.84) with the degrees of freedom (1 and 541 ) and at 0.05 alpha level, leading to the rejection of the null hypothesis. Therefore there was significant relationship between oral health behavior and oral health attitude of the 
pensioners. Further analysis of the relationship in a regression model showed that the p-value $(0.000)$ was less than 0.05 alpha level, this further confirmed the significant relationship between oral health attitude and behavior.

\section{Discussions}

Overall, about two-third of the pensioners had poor knowledge of oral health. Approximately, $60 \%$ had poor oral health behavior and two-third had negative attitude toward oral health. This indicated that the oral health knowledge, attitude and behavior of the pensioners were poor and there is the need for oral health education and motivation in this group. This result is comparable to the result obtained in the study of Al-Sharbatti and Sadek in 2014 [17]. This study showed that among those 60 years and above, $87.9 \%$ of the participants had poor behavior and $62 \%$ had poor knowledge. The findings of Braimoh and Owoturo are at variance to the findings of the present study [18], they reported that $65 \%$ of their sample had good knowledge, $63 \%$ had positive attitude and $60 \%$ had good behavior. The high level of knowledge, positive attitude and behavior exhibited by the participants as compared to the population in the present study may be attributed the fact that the population in their study was medical, pharmacy and nursing students who are exposed to lectures on oral health.

Oral health knowledge was significantly related to the behavior of the pensioners. The knowledge of oral heath accounted for $43.56 \%$ of the variance in the behavior of the pensioners $\left(\mathrm{R}^{2}=0.4356\right)$, indicating that oral health knowledge predicted the oral health behavior of the pensioners by $43.56 \%$. Regression coefficient $(\mathrm{R})$ of the relationship between oral health knowledge and behavior was 0.6, indicating moderate and positive relationship between the variables. This implies that as the knowledge of the pensioners increased there was improvement in their behavior. These findings are in consonance with the knowledge, attitude and behavior model (KAB model) of health education which suggests that acquiring new knowledge would alter attitudes and lead to a behavioral change [19].

These results are similar to those obtained from several other studies. For instance, Hamilton and Coulby reported that increase in oral health knowledge was positively correlated with improved behavior and stated that knowledge of health is an important predictor for behavior [4]. The result of Hamilton and Coulby was further confirmed by Ashley [20]. Freeman et al. [21] in their study stated that those who have a greater knowledge of oral health practices and are confident in their control over their oral health, are more likely to positive oral health behavior. Singh et al. [22] reported a linear positive relationship between oral health knowledge and behavior. Sharda and Shetty [23] and Braimoh and Owoturo [18] reported non-significant linear relationship between oral health behavior and knowledge.

Oral health attitude was significantly related to the behavior of the pensioners. Oral health attitude accounted for $22.01 \%$ of the variance in the oral health behavior of the pensioners $\left(\mathrm{R}^{2}=0.2201\right)$, indicating that oral health attitude predicted the oral health behavior of the pensioners by $22.01 \%$. The regression coefficient $(\mathrm{R})$ of the association between attitude and behavior was 0.47 , suggesting low and positive relationship between oral health attitude and behavior. This suggests that a change in attitude from negative to positive would lead to a change in behavior from poor to good. These findings are in agreement with the findings of Daly [19], who reported that positive attitude would lead to improved health behavior. Hamilton and Coulby [4] and Ashley [20] had earlier reported that increase in oral health attitude is positively correlated with improved behavior. Singh et al. [22] reported a linear positive relationship oral health attitude and behavior. Similarly, Sharda and Shetty [23] and Braimoh and Owoturo [18] reported statistically significant linear relationship between oral health behavior and the attitude.

\section{Conclusion}

The present study revealed that the majority of the elderly had poor oral health knowledge and behavior as well as negative attitude towards oral health. There was also significant moderate and positive relationship between oral health knowledge and behavior as well as between oral health attitude and behavior. There is therefore the need to educate this group on appropriate self-care and regular dental visits as a cornerstone to the promotion of oral health and prevention of oral diseases. Information on oral health and dental care should be disseminated to the pensioners and the public through dental health care workers, media and public oral health outreach programmes.

\section{References}

[1] Sheiham A. Changing trends in dental caries. Int J Epidemiol 1984; 13: 142-147.

[2] Glanz K, Rimer BK, Lewis FM. Health Behavior and Health Education 3rd ed. San Francisco, Jossey-Bass. 2002.

[3] Woodgroove J, Cumberbatch G, Gylbier S. Understanding dental attendance behavior. Community Dent Health 1987; 4: 215-221.

[4] Hamilton ME, Conlby WM. Oral health knowledge and habits of senior elementary school students. J Pub Health Dent 1991; 51: 212-218.

[5] Al-Ansari J, Honkala E, Honkala S. Oral health knowledge and behavior among male health sciences college students in Kuwait. BMC Oral Health 2003; 3(2).

[6] Marmot M, Bell R. Social determinants and dental health. Adv Dent Res 2011; 23:201-206.

[7] Kirscht JP. Preventive Health Behavior. A review of research and issues. Health Psycho 1983; 12: 277-301. 
[8] DeBarr KA. A review of current health education theories. Cal J Health Pro 2004; 2(1): 74-87.

[9] National Cancer Institute. Theory at a Glance: A Guide for Health Promotion Practice. Washington, DC: U. S. Department of Health and Human Services. 2003.

[10] United Nation Population Division. World population prospect: The 2002 revision. New York, United Nations. (2003).

[11] Nwankwo OC. Practical guide to research writing $5^{\text {th }}$ ed. Choba, Port Harcourt, University of Port Harcourt Press Limited. 2013.

[12] Nworgu BG. Educational research: Basic issues and methodology. Ibadan, Wisdom Publishers Limited. 1991.

[13] Lwanga SK, Lemeshow S. Sample size determination in Health studies: A Practical Manual. World Health Organisation, Geneva. 1991.

[14] Esan TA, Oziegbe EO. Oral health status and treatment needs of elderly people in Ile-ife, Nigeria. East Afri J Pub Health 2013; 10(3): 535-538.

[15] Kumar R. A step by step for beginners. Research methodology ( $3^{\text {rd }}$ ed.) New Delhi, SAGE. 2011.

[16] Nwana BG. Introduction to educational research. Ibadan, Heinemann Educational Book Nigeria Limited. (1992).
[17] Al-Sharbatti S, Sadek M. Oral Health Knowledge, Attitudes and Practices of the elderly in Ajman, UAE. Gulf Med J 2014; 3(S2): S152-S164.

[18] Braimoh OB, Owoturo EO. Oral Health Knowledge, Attitude and Behavior of Medical, Pharmacy and Nursing Students at the University of Port Harcourt, Nigeria. J Oral Res Rev 2016, 8(2): 66-71.

[19] Daly R. Text book of Essentials in Dental Public Health. New York, Oxford University Press. 2005.

[20] Ashley FP. Role of dental health education in preventive dentistry, In Murry, J. J. (Ed.), Prevention of dental disease (406-414). Oxford: Oxford University Press. 1996.

[21] Freeman R, Maizels J, Wyllie M, Sheiham A. The relationship between health related knowledge, attitudes, and dental health behaviors in 14-16 year old adolescents. Community Dent Health 1993; 10: 397-404.

[22] Singh K, Kochhar S, Mittal V, Agrawal A, Chaudhary H, Anandani C. Oral health: knowledge, attitude and behavior among Indian population. Educ Res 2012; 3(1): 66-71.

[23] Sharda AJ, Shetty S. A comparative study of oral health knowledge, attitude and behavior of non-medical, paramedical and medical students in Udaipur city, Rajasthan, Indian Int J Dent Hyg 2010; 8: 101-109. 